\title{
Blood group antigens $\mathrm{A}, \mathrm{B}, \mathrm{H}, \mathrm{Le}^{\mathrm{a}}, \mathrm{Le}^{\mathrm{b}}$, and $\mathrm{I}(\mathrm{Ma})$ in resting and tetragastrin stimulated gastric juice of patients with non-neoplastic diseases of the stomach
}

\author{
JEAN K PICARD,${ }^{*}$ KYOKO HOTTA,$\dagger$ TEN FEIZI* \\ From the *Applied Immunochemistry Research Group, Clinical Research Centre, Harrow, Middlesex, and \\ the $\dagger$ Department of Biochemistry, School of Medicine, Kitasato University, Sagamihara, 228 Japan
}

SUMMARY In view of the anomalous expression of blood group and related antigens in the gastric mucosae of patients with malignant and premalignant diseases of the stomach, and the potential clinical value of their measurement, a preliminary study has been performed on the blood group antigens $\mathrm{A}, \mathrm{B}, \mathrm{H}, \mathrm{Le}^{\mathrm{a}}, \mathrm{Le}^{\mathrm{b}}$, and $\mathrm{I}(\mathrm{Ma})$ in glycoprotein rich extracts of the resting and tetragastrin stimulated gastric juice of patients without evidence of gastric cancer. The aim has been to assess whether the antigenic profiles known to distinguish the gastric mucosae of secretors from those of non-secretors are reflected in the glycoproteins of gastric juice. Antigenic profiles which distinguish secretors from non-secretors were observed in the stimulated rather than the resting gastric juice as follows: the $\mathrm{A}, \mathrm{B}$ or $\mathrm{H}$ antigens but not $\mathrm{I}(\mathrm{Ma})$ were strongly expressed in the glycoproteins of secretors, while I(Ma) was the antigen characteristic of nonsecretors. On the other hand, there was considerable overlap in the $\mathrm{Le}^{\mathrm{a}}$ and $\mathrm{Le}^{\mathrm{b}}$ antigen values in the resting and stimulated gastric juice of secretors and non-secretors. Among these antigens, $\mathrm{I}(\mathrm{Ma})$ is known to appear as a neo-antigen in the gastric mucosae of secretors with malignant and premalignant diseases of the stomach. Thus this antigenic determinant is potentially a clinically useful marker in the gastric juice of $75 \%$ of the population who are secretors. The clinical value of the levels of this antigen in the gastric juice now deserves investigation.

It is well established ${ }^{1}$ that glycoproteins of the gastric mucosa normally express the blood group A, B $\mathrm{H}, \mathrm{Le}^{\mathrm{a}}, \mathrm{Le}^{\mathrm{b}}$, and $\mathrm{I}(\mathrm{Ma})$ antigens in accordance with the red cell type and the secretor status of individuals. In secretors, these glycoproteins express the A, $B, H$, and $L e^{b}$ antigens. On the other hand, in nonsecretors (due to the absence of the blood group $\mathrm{H}$-fucosyltransferase in the epithelial cells) these antigens are lacking; instead, antigens associated with their biosynthetic precursors-namely, I(Ma) and $\mathrm{Le}^{\mathrm{a}}$ antigens-are expressed. These genetically predicted patterns of antigen expression often change in gastric cancer tissues. The changes are most readily detected in secretors in whose tumours the $A, B, H$, and $L^{b}$ antigens may be diminished or deleted (possibly due to incomplete biosynthesis ${ }^{2}$ of carbohydrate chains), and an increased expression of the I(Ma) and Le $\mathrm{L}^{\mathrm{a}}$ antigens often occurs. ${ }^{3}$ Thus glycoproteins extracted from the gastric tumours of secretors acquire some of the antigenic characteris-

Accepted for publication 6 November 1984 tics that are normally associated with the mucosal glycoproteins of non-secretors.

By means of immunofluorescence, Kapadia et $\mathrm{al}^{4}$ have shown that anomalous expression of these carbohydrate antigens is not confined to gastric cancer cells but also occurs in focal areas of the gastric mucosa in patients with chronic benign gastric pathology, especially those with intestinal metaplasia, which is regarded by some to be a preneoplastic condition. These observations have raised the possibility that changes in the patterns of expression of these blood group related antigens may be valuable as early biochemical markers of neoplastic and preneoplastic states. ${ }^{4}$

The appearance of new antigens rather than a reduction of normally expressed antigens would be ideal for the screening and follow up of populations at risk of developing gastric cancer. Thus if the I(Ma) and $\mathrm{Le}^{\mathrm{a}}$ antigens could be reliably detected as "neo-antigens" in aspirates of the gastric juice of secretors (as in their mucosal glycoproteins) they would be potentially useful antigenic markers in $75 \%$ of the population who are secretors. 
Table 1 Patients included in the study

\begin{tabular}{|c|c|c|c|c|}
\hline Case no & Sex & Age & $\begin{array}{l}\text { Blood group and } \\
\text { secretor status }\end{array}$ & Diagnosis \\
\hline $\begin{array}{l}1783 \\
1784 \\
1785 \\
1786 \\
1787 \\
1788 \\
1789 \\
1790 \\
1791 \\
1792 \\
1793 \\
1794 \\
1795 \\
1796 \\
1797\end{array}$ & $\begin{array}{l}\mathbf{F} \\
\mathbf{F} \\
\mathbf{M} \\
\mathbf{F} \\
\mathbf{M} \\
\mathbf{M} \\
\mathbf{M} \\
\mathbf{M} \\
\mathbf{F} \\
\mathbf{F} \\
\mathbf{F} \\
\mathbf{M} \\
\mathbf{M} \\
\mathbf{M} \\
\mathbf{M}\end{array}$ & $\begin{array}{l}49 \\
44 \\
29 \\
41 \\
44 \\
39 \\
48 \\
63 \\
64 \\
40 \\
31 \\
40 \\
13 \\
53 \\
57\end{array}$ & $\begin{array}{l}\text { AB, s } \\
\text { B, s } \\
\text { B,s } \\
\text { A,s } \\
\text { A, ns } \\
\text { O,s } \\
\text { A, ns } \\
\text { A,s } \\
\text { B,s } \\
\text { O,s } \\
\text { A,s } \\
\text { O, ns } \\
\text { O,s } \\
\text { B, s } \\
\text { O,s }\end{array}$ & $\begin{array}{l}\text { Gastritis erosiva } \\
\text { Menetrier's disease } \\
\text { Duodenal ulcer } \\
\text { Duodenal ulcer } \\
\text { Duodenal ulcer } \\
\text { Duodenal ulcer } \\
\text { Duodenal ulcer } \\
\text { Oesophageal ulcer } \\
\text { Oesophageal ulcer } \\
\text { Pyloric stenosis } \\
\text { Von Recklinghausen disease } \\
\text { Gastric ulcer } \\
\text { Duodenal ulcer } \\
\text { Duodenal ulcer } \\
\text { Gastric ulcer }\end{array}$ \\
\hline
\end{tabular}

$\mathrm{s}=$ secretor: $\mathrm{ns}=$ non-secretor.

In the present studies we have assayed the I(Ma), $\mathrm{A}, \mathrm{B}, \mathrm{H}, \mathrm{Le}^{\mathrm{a}}$, and $\mathrm{Le}^{\mathrm{b}}$ antigens in glycoprotein extracts of paired samples of gastric juice obtained in the resting state and after stimulation of gastric secretion with tetragastrin. We present evidence for the occurrence of substantial degradation of carbohydrate chains in the resting gastric juice, with a resulting deviation from the normal antigen profiles. In stimulated gastric juice, however, the normal pat- terns of expression of the $\mathrm{I}(\mathrm{Ma}), \mathrm{A}, \mathrm{B}$, and $\mathrm{H}$ antigens are well preserved.

\section{Material and methods}

PATIENTS AND GASTRIC JUICE SAMPLES

Fifteen patients with non-neoplastic conditions of the stomach, duodenum, or oesophagus were studied (Table 1). After overnight fasting, the gas-

Table 2 Yields of glycoproteins from the resting and stimulated gastric juice of the 15 patients studied

\begin{tabular}{|c|c|c|c|c|c|c|}
\hline \multirow[t]{2}{*}{ Case no } & \multirow[t]{2}{*}{ Sample* } & \multirow[t]{2}{*}{ Volume (ml) } & \multirow[t]{2}{*}{$p H$} & \multirow{2}{*}{$\begin{array}{l}\text { Ethanol } \\
\text { precipitate (mg) }\end{array}$} & \multicolumn{2}{|c|}{ Pepsin digest } \\
\hline & & & & & Yield (mg) & \% Hexose \\
\hline 1783 & $\mathbf{F}$ & 20 & $2 \cdot 86$ & 30 & $10 \cdot 9$ & 34 \\
\hline & $\mathbf{S}$ & 240 & 1.56 & 374 & $77 \cdot 9$ & 31 \\
\hline 1784 & $\mathbf{F}$ & $\begin{array}{r}54 \\
206\end{array}$ & $7 \cdot 35$ & 212 & 77.8 & 34 \\
\hline 1785 & $\mathbf{S}$ & $\begin{array}{r}206 \\
72\end{array}$ & 6.83 & $\begin{array}{r}576 \\
88\end{array}$ & $245 \cdot 2$ & 20 \\
\hline 1700 & $\mathbf{S}$ & 340 & $\begin{array}{l}1.59 \\
1.38\end{array}$ & $\begin{array}{r}88 \\
306\end{array}$ & $\begin{array}{l}22 \cdot 0 \\
23.7\end{array}$ & $\begin{array}{l}39 \\
31\end{array}$ \\
\hline \multirow[t]{2}{*}{1786} & $\vec{F}$ & $-t$ & 1 & - & - & - \\
\hline & $\mathbf{S}$ & 74 & $4 \cdot 1$ & 302 & 87.5 & 28 \\
\hline 1787 & $\mathbf{F}$ & 48 & 1.82 & 94 & $14 \cdot 3$ & 34 \\
\hline & $\mathbf{S}$ & 325 & $1 \cdot 42$ & 232 & 28.4 & 34 \\
\hline 1788 & $\mathbf{F}$ & 70 & $3 \cdot 7$ & 224 & $28 \cdot 8$ & 31 \\
\hline 1789 & $S$ & 185 & $1 \cdot 64$ & 340 & $51 \cdot 1$ & 34 \\
\hline $1 / 89$ & $\mathbf{F}$ & 17 & $1 \cdot 87$ & 82 & $15 \cdot 3$ & 39 \\
\hline 1790 & $\vec{F}$ & 31 & $\begin{array}{l}1.31 \\
8 \cdot 77\end{array}$ & $\begin{array}{r}220 \\
76\end{array}$ & $\begin{array}{l}27 \cdot 1 \\
27 \cdot 5\end{array}$ & 30 \\
\hline & $\mathbf{S}$ & 94 & $7 \cdot 08$ & 406 & $129 \cdot 2$ & 28 \\
\hline 1791 & $\mathbf{F}$ & 10 & $2 \cdot 72$ & 35 & $12 \cdot 7$ & 34 \\
\hline & $\mathbf{S}$ & 86 & $1 \cdot 37$ & 32 & $6 \cdot 8$ & 36 \\
\hline 1792 & $\mathbf{F}$ & 6 & $1 \cdot 58$ & 22 & $6 \cdot 3$ & 31 \\
\hline & $\mathbf{S}$ & 130 & $1 \cdot 37$ & 209 & 19.7 & 31 \\
\hline 1793 & $\mathbf{F}$ & 31 & 1.97 & 200 & $24 \cdot 9$ & 27 \\
\hline & $\mathbf{S}$ & 166 & 1.49 & 341 & $48 \cdot 4$ & 18 \\
\hline 1794 & $\mathbf{F}$ & 40 & $6 \cdot 17$ & 140 & $25 \cdot 2$ & 34 \\
\hline & $\mathbf{S}$ & 455 & $1 \cdot 38$ & 450 & $41 \cdot 2$ & 25 \\
\hline 1795 & $\mathbf{F}$ & 94 & $1 \cdot 76$ & 206 & $34 \cdot 9$ & 34 \\
\hline 1796 & $\mathbf{S}$ & 175 & 1.63 & 340 & $47 \cdot 5$ & 36 \\
\hline & $\mathrm{S}$ & 160 & 1.47 & 348 & 47.4 & 34 \\
\hline 1797 & $\mathbf{F}$ & 1 & $2 \cdot 52$ & - & - & $105 \mu g \ddagger$ \\
\hline & $\mathbf{S}$ & 146 & $1 \cdot 32$ & 154 & $17 \cdot 1$ & 38 \\
\hline
\end{tabular}

${ }^{*} F$ and $S$ designate fasting and tetragastrin stimulated gastric juice respectively.

tA fasting sample was not tested from this case.

$\ddagger$ The amount of extract was too small for weighing. The yield was expressed as total hexose ( $\mu \mathrm{g})$. 
tric tube was positioned in the distal antrum, and the fasting gastric juice was aspirated and discarded. In separate studies we (Feizi T, Picard J, Kapadia A, Reed $P$, unpublished observations) have shown that the patterns of antigen expression in fasting gastric juice are not sufficiently reliable for discerning secretors from non-secretors. Gastric juice was then collected for $1 \mathrm{~h}$ (resting gastric juice). Tetragastrin was then administered intravenously $(4 \mu \mathrm{g} / \mathrm{kg}$ body weight) and gastric juice was collected for a further hour (stimulated gastric juice). The volume and $\mathrm{pH}$ of each sample were noted, and those samples with $\mathrm{pH}$ values below 7 were neutralised immediately with $2 \mathrm{M}$ Tris- $\mathrm{HCl}$ buffer, $\mathrm{pH} 8 \cdot 4$, to $\mathrm{pH} 7$ using a $\mathrm{pH}$ meter. Only juice that was not visibly contaminated with bile, blood, and food was used. Neutralised juice was centrifuged at $1500 \mathrm{~g}$ for $20 \mathrm{~min}$ at $4^{\circ} \mathrm{C}$ and the precipitate was discarded. Glycoproteins were precipitated from the supernatant gastric juice by adding absolute alcohol to a final concentration of $70 \%$ ( vol/vol). After standing for $1 \mathrm{~h}$ at $4^{\circ} \mathrm{C}$ the precipitates were removed by centrifugation at

\begin{tabular}{|c|c|}
\hline Designation & Structure \\
\hline$I(\mathrm{Ma})$ & Gal $\beta 1-\angle G I c N A c \beta 1$ \\
\hline H(Ulex) & $\begin{array}{l}\text { Gal } \beta 1-\angle G I C N A C \\
\mid 1.2 \\
\text { Fuc } \alpha\end{array}$ \\
\hline$H$ (Bombay) & $\begin{array}{l}\text { Gal } \beta 1-3 G \mid c N A c \\
\mid 1.2 \\
\text { Fuc } \alpha\end{array}$ \\
\hline A & 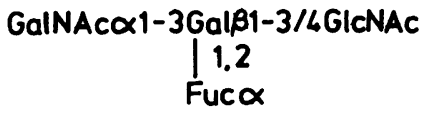 \\
\hline B & $\begin{array}{c}\text { Gal } \propto 1-3 \text { GalB1-3/4GlcNAC } \\
\mid 1,2 \\
\text { Fuc } \alpha\end{array}$ \\
\hline $\operatorname{Le}^{a}$ & $\begin{array}{c}\text { Gal } 1-3 \text { GlcNAC } \\
\mid 1,4 \\
\text { Fuc } \alpha\end{array}$ \\
\hline Le $b$ & $\begin{array}{l}\text { Gal } \beta 1-3 \text { GIcNAC } \\
|1.2| 1.6 \\
\text { Fuc } \alpha \text { Fuc } \alpha\end{array}$ \\
\hline
\end{tabular}

Fig. 1 Structures of the carbohydrate antigens recognised by anti-I(Ma), Ulex Europeus, anti-H (Bombay) serum, anti- $A$, anti- $B$, anti-L $e^{a}$ and anti- $L e^{b}$.
$3000 \mathrm{rpm}$ for $20 \mathrm{~min}$ and washed twice with $70 \%$ ethanol and lyophilised.

The lyophilised samples were subjected to pepsin digestion followed by ethanol precipitation, as described previously. ${ }^{3}$ The average yields of extract (dry weight), as a percentage of the original ethanol precipitable material, were $23 \%$ for the resting juice and $17 \%$ for the stimulated juice (Table 2). Average hexose contents of the extracts (measured by phenol sulphuric assay ${ }^{5}$ ) were $32 \%$ in the resting juices and $30 \%$ in the stimulated juices.

\section{DETERMINATION OF SECRETOR STATUS}

The secretor status of each patient was assessed by examination of their saliva for blood group A, B and $\mathrm{H}$ antigens, as described previously. ${ }^{3}$ Twelve patients were secretors and three were nonsecretors (Table 1).

\section{REAGENTS}

The blood grouping reagents were as described previously. ${ }^{3}$ Anti- $A$, anti-B, anti- $\mathrm{Le}^{\mathrm{a}}$, and anti- $\mathrm{Le}^{\mathrm{b}}$ sera

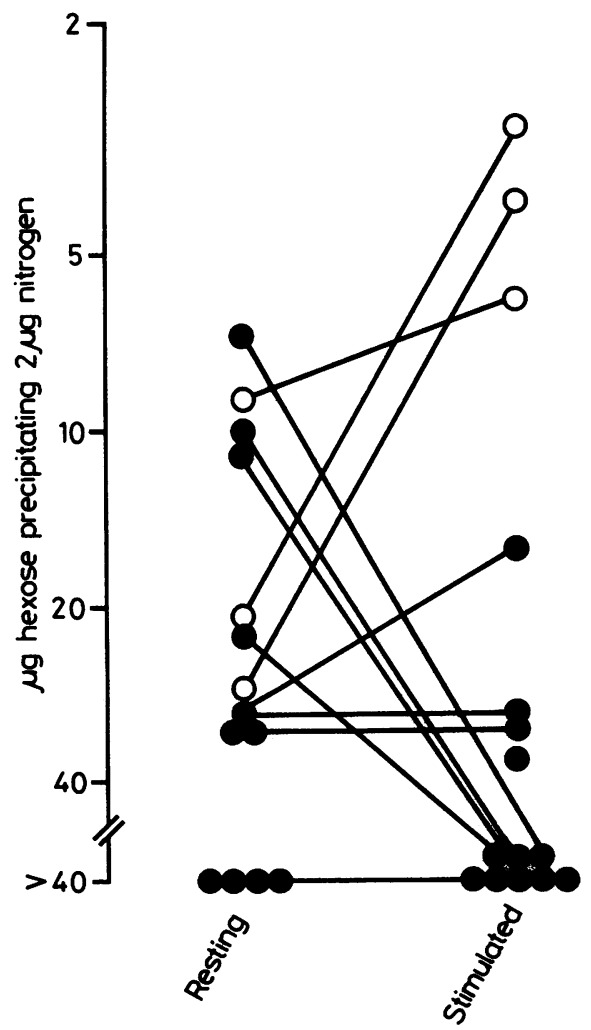

Fig. 2 Quantitative precipitin assays of I(Ma) antigen activities of glycoprotein extracts of resting and stimulated gastric juice of 12 secretors $(\odot)$ and three non-secretors $(O)$. 


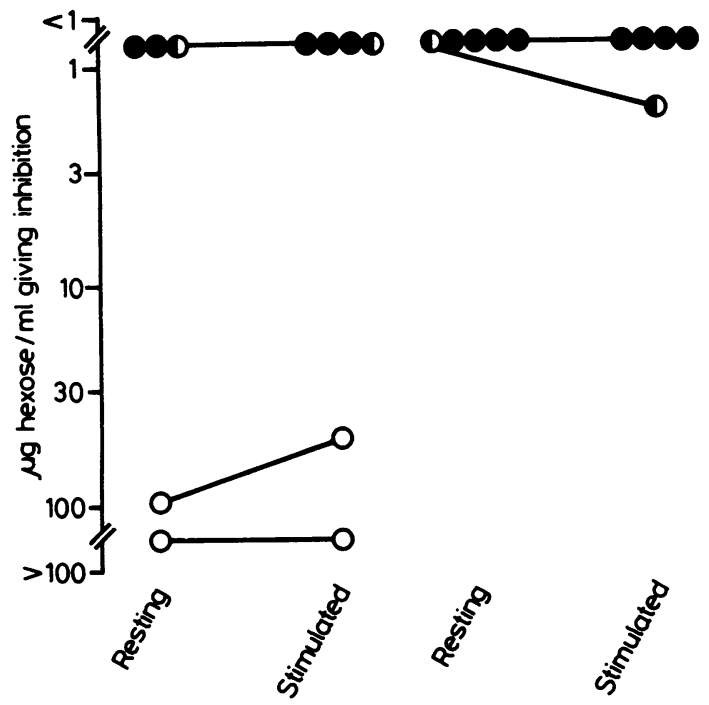

Fig. 3 Haemagglutination inhibition assays of the blood group $A$ and $B$ antigens (left and right panels, respectively) in the resting and stimulated gastric juice of patients of blood groups $A, B$, and $A B$. Symbols are as in Fig. 2 except that the results with the single patient of blood $A B$ are shown in both panels and designated (O).

were obtained from Behring Diagnostics (Hoechst Pharmaceuticals, Hounslow, UK); anti-H from Ulex europaeus seeds was purchased from Dade Laboratories (American Hospital Supplies Corporation. Miami, Florida, USA). Anti-I(Ma) is a monoclonal cold agglutinin from a patient with chronic cold haemagglutinin disease. The carbohydrate determinants recognised by these reagents are shown in Fig. 1. Anti-I(Ma) recognises a major category of backbone structure (Gal $\beta 1-4 \mathrm{GlcNAc}$, termed type 2) which occurs as a branch joined by 1-6 linkage to galactose or $\mathrm{N}$-acetylgalactosamine residues of mucin type glycoproteins. ${ }^{6}$ The Ulex lectin recognises the blood group $\mathrm{H}$ structure formed by the addition of $\alpha 1-2$ linked fucose to a type 2 backbone sequence, ${ }^{7}$ whereas anti- $\mathrm{H}$ antibodies of the Bombay serum used react preferentially with the blood group $H$ structure on type 1 (Gal $\beta 1$ 3GlcNAc) backbones (Picard $J$ and Feizi $T$, unpublished observations). The A and B antigenic determinants consist of $\mathrm{N}$-acetylgalactosamine or galactose residues joined by $\alpha 1-3$ linkage to blood group $H$ structures on type 1 or type 2 backbones and the $\mathrm{Le}^{\mathrm{a}}$ and $\mathrm{Le}^{\mathrm{b}}$ antigens consist of mono and difucosylated type 1 chains respectively. ${ }^{8}$
HAEMAGGLUTINATION INHIBITION ASSAYS

$A, B, H, \mathrm{Le}^{a}$, and $\mathrm{Le}^{\mathrm{b}}$ activities of the gastric juice extracts were measured in haemagglutination inhibition assays as described previously. ${ }^{3}$ Results were expressed as the minimum concentration of extracts ( $\mu \mathrm{g} \mathrm{hexose} / \mathrm{ml}$ ) giving complete inhibition of eight haemagglutinating units of reagent.

\section{QUANTITATIVE PRECIPITATION ASSAYS}

I(Ma) activities were measured in quantitative precipitin assays as described previously. ${ }^{3}$ Results are expressed as the quantity of extract ( $\mu \mathrm{g}$ hexose) required to precipitate $2 \mu \mathrm{g}$ of antibody nitrogen.

\section{Results}

\section{I(Ma) ANTIGEN}

The distinction between secretors and non-secretors could be clearly made using stimulated but not the resting gastric juice (Fig. 2). In the resting gastric juice extracts there was low expression of this antigen in two of the three non-secretors studied, and substantial activity was found in three of the 11 secretors. In contrast, in the stimulated gastric juice this antigen was strongly expressed only in the nonsecretors.

BLOOD GROUP A, B, AND H ANTIGENS

The $A$ and $B$ antigens were strongly expressed in

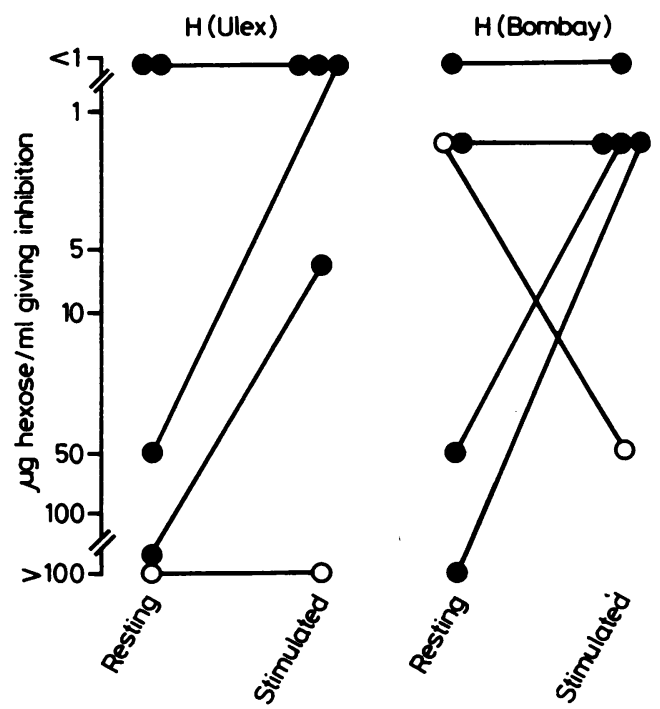

Fig. 4 Haemagglutination inhibition assays of the blood group $\boldsymbol{H}$ determinants reactive with Ulex Europeus lectin and anti-H (Bombay) serum in the resting and stimulated gastric juice of five blood group $O$ patients. Symbols as in Fig. 2. 


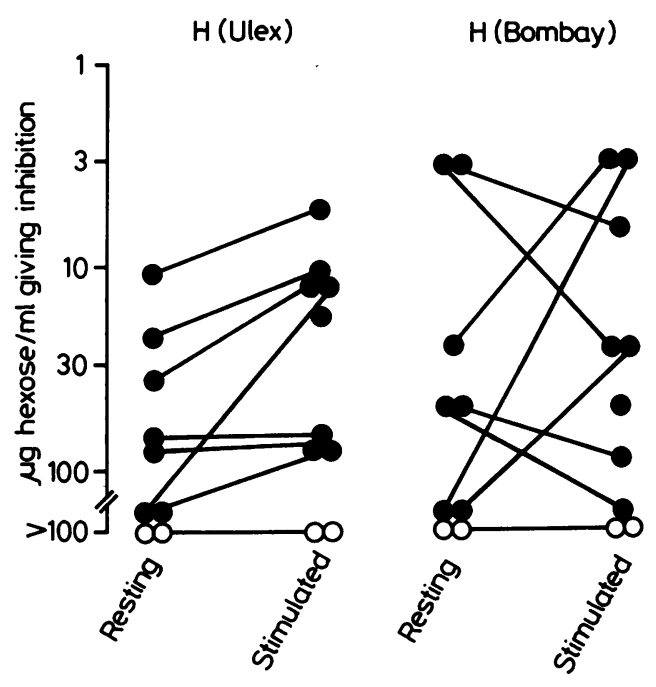

Fig. 5 Haemagglutination inhibition assays of the blood group $\boldsymbol{H}$ determinants reactive with Ulex Europeus lectin and anti-H (Bombay) serum in the resting and stimulated gastric juice glycoproteins of patients of blood groups $A, B$ or AB. Symbols as in Fig. 2.

glycoprotein extracts derived from blood group A and $B$ secretors, both in the resting state and after stimulation with tetragastrin, and there was a clear distinction between the antigen concentrations in secretors and non-secretors (Fig. 3).

The same could not be said about the $\mathrm{H}$ antigen in group $\mathrm{O}$ persons: a distinction of secretors from non-secretors could be made only using stimulated gastric juice. The reactivities with Ulex lectin, which recognises the type 2 based $\mathrm{H}$ structure (Fig. 1), were extremely low in the resting juice of two of the four group $O$ secretors (Fig. 4). In most of the secretors of blood groups $\mathrm{A}, \mathrm{B}$, or $\mathrm{AB}$ reactivities with Ulex lectin were also lower in the resting than in the stimulated gastric juice (Fig. 5).

The $\mathrm{H}$ activity, as determined with Bombay serum, which recognises predominantly type 1 based blood group antigen, was also low in the resting juice of two of the four group $O$ secretors, and increased after tetragastrin stimulation (Fig. 4). The reactivities in the group $A, B$, and $A B$ secretors were variable; there was increased reactivity in five of these patients after stimulation and a reduced reactivity in the remaining six (Fig. 5). There was an unexpected reactivity in the resting juice of a group O non-secretor (case 1794) but not in the stimulated gastric juice from this patient.

LE $^{a}$ AND LE ${ }^{b}$ ANTIGENS

With the exception of two cases there was little dif- ference in the expression of these antigens between the resting and stimulated extracts, and there was no clear distinction between secretors and nonsecretors (Fig. 6). The non-secretor patient with a high Le $^{\mathrm{b}}$ value in the resting but not in the stimulated juice was case 1794, whose resting juice also showed high blood group $\mathrm{H}$ activity.

\section{Discussion}

The antigenicity of glycoproteins of the gastric juice may be affected by $(a)$ degradation of the carbohydrate chains and $(b)$ contamination with salivary, pancreatic, and intestinal secretions. Both of these possibilities are more likely to occur in the resting gastric juice. The saliva is a rich source of $\mathrm{I}(\mathrm{Ma})$ antigen" (Feizi $\mathrm{T}$, unpublished observations), and pancreatic secretions contain blood group A, B, and $\mathrm{H}$ activities both in secretors and non-secretors. ${ }^{10}$ Thus salivary contamination may contribute to the high levels of $\mathrm{I}(\mathrm{Ma})$ activities noted in the resting gastric juice of secretors, and pancreatic juice contamination may have been responsible for the unexpected finding of $\mathrm{H}$ (Bombay) antigen activity in the resting gastric juice of one of the group $\mathrm{O}$ nonsecretors.

While the $A$ and $B$ antigen activities were well preserved in the resting gastric juice, there was evidence of substantial degradation of the blood group $\mathrm{H}$ determinant in the samples of resting gastric juice

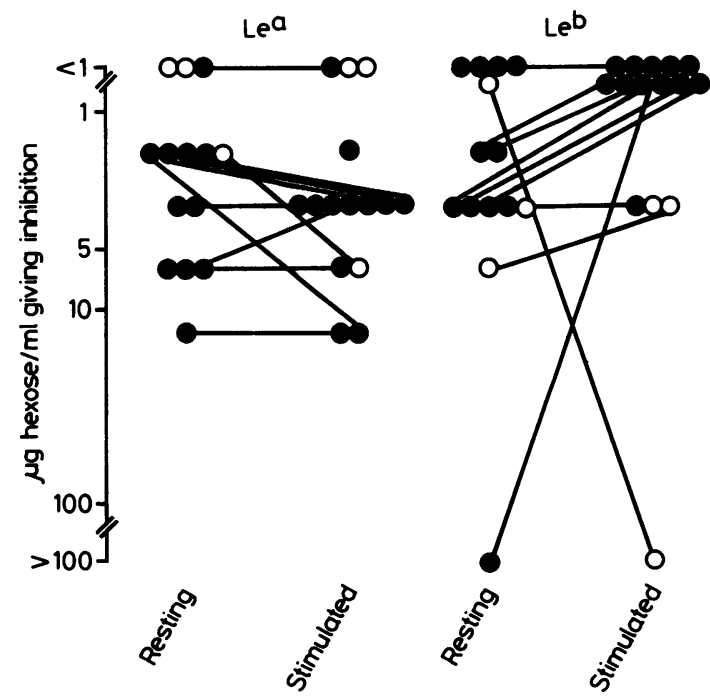

Fig. 6 Haemagglutination inhibition assays with anti-Le $e^{a}$ and $-L e^{b}$ antibodies using glycoprotein extracts of resting and stimulated gastric juice of patients included in these studies. Symbols as in Fig. 2. 
of a high proportion of secretors as follows: the $\mathrm{H}$ determinant recognised by Ulex lectin was lower in all but two of the resting samples in secretors of all blood groups. The $\mathrm{H}$ determinant recognised by the Bombay reagent was also much reduced in two of the four group $O$ secretors and about half of the group $\mathrm{A}, \mathrm{B}$, and $\mathrm{AB}$ secretors. The finding of lower levels of $\mathrm{H}$ (Bombay) determinant in the stimulated gastric juice of the remaining secretors of blood groups $A, B$, and $A B$ groups may represent the masking of this determinant by the $\mathrm{A}$ and $\mathrm{B}$ monosaccharides $^{8}$ in the freshly secreted glycoproteins. Taken together these observations point to a high susceptibility of the $\alpha 1-2$ linked fucose residue (associated with $\mathrm{H}$ antigen activity) to hydrolysis by the acid medium or endogenous fucosidases, or both, in the gastric juice.

Loss of the blood group $\mathrm{H}$ fucose on type 2 backbone structures would reveal I(Ma) antigen activity that is normally masked in the glycoproteins of secretors, ${ }^{6}$ and this is a second possible cause of the high levels of expression of this antigen in the gastric juice of secretors. It is of interest that the three secretors with the highest levels of I(Ma) antigen in the resting gastric juice extracts were blood group $\mathrm{O}$ individuals. The number of cases is small, but these observations raise the possibility that the blood group $\mathrm{H}$ fucose in the gastric glycoproteins of group $O$ persons may be more susceptible to degradation than that in $A$ or $A B$ persons. In these latter individuals the presence of the blood group $A$ and $B$ monosaccharides, $\mathrm{N}$-acetylgalactosamine and galactose, respectively, may have a protective effect.

The finding of lower $\mathrm{I}(\mathrm{Ma})$ levels in the resting gastric juice of non-secretors than in their stimulated gastric juice suggests that degradation of terminal $\beta 1-4$ linked galactose residues may also occur in the shed gastric glycoproteins.

As discussed above, the A and B antigenic determinants were well preserved in the resting gastric juice. Thus any loss of the fucose residues that may occur in the resting juice did not affect perceptibly the expression of the $A$ and $B$ antigens. Although the presence of the $\alpha 1-2$ linked fucose is essential for the transfer of blood groups A and B associated $\mathrm{N}$-acetylgalactosamine and galactose residues respectively by the $A$ and $B$ glycosyl transferases, the presence of the fucose residues may not be essential for reactivity with anti-A and anti-B antibodies."

Unlike the findings with the A, B, H, and I(Ma) antigens, there was considerable overlap in the $\mathrm{Le}^{\mathrm{a}}$ and $\mathrm{Le}^{\mathrm{b}}$ antigen values in the resting and stimulated gastric juice of secretors and non-secretors. This is in contrast to previous observations on glycoprotein extracts derived from surgically excised gastric mucosae and from washed gastric mucins. A clear distinction among secretors and non-secretors was found ${ }^{3}$ : Le ${ }^{a}$ activity was substantially higher in nonsecretors and $\mathrm{Le}^{\mathrm{b}}$ in secretors.

The present studies show that levels of I(Ma) antigen in stimulated gastric juice clearly distinguish secretors with low or undetectable levels from nonsecretors with high levels of this antigen. Studies of this antigen as well as a number of hybridoma defined, blood group related carbohydrate antigens, reviewed elsewhere ${ }^{12} 13$ should now be performed* using the stimulated gastric juice of patients with known neoplastic or pre-neoplastic changes in the gastric mucosa, in the hope of assessing their value as early biochemical markers of malignant or premalignant disease of the gastric mucosa.

*The type 1 based antigens recognised by hybridoma antibodies FC $10 \cdot 2^{14}$ and
$19 \cdot 9^{15}$ are also potentially useful antigenic markers which have been found as
normal components in glycoprotein extracts of the gastric mucosa in non-
secretors and as tumour associated antigens in those of secretors. ${ }^{16}$ The latter
antigen could not be assayed in the present studies because the acid pH during
the pepsin digestion procedure results in a substantial loss of the sialic acid
residues.

References

' Feizi T. Blood group antigens and gastric cancer. Med Biol 1982;60:7-11.

${ }^{2}$ Hakomori S, Young Jr WW. Tumour-associated glycolipid antigens and modified blood group antigens. Scand J Immunol 1978;7 (suppl 6):97-117.

${ }^{3}$ Picard J, Waldron-Edward D, Feizi T. Changes in the expression of the blood group $\mathrm{A}, \mathrm{B}, \mathrm{H}, \mathrm{Le}^{\mathrm{a}}$ and $\mathrm{Le}^{\mathrm{b}}$ antigens and the blood group precursor associated $\mathrm{I}(\mathrm{Ma})$ antigen in glycoprotein-rich extracts of gastric carcinomas. J Clin Lab Immunol 1978; 1:119-28.

4 Kapadia A, Feizi T, Jewell D, Keeling J, Slavin G. Immunocytochemical studies of blood group $A, H, I$ and antigens in gastric mucosae of infants with normal gastric histology and of patients with gastric carcinoma and chronic benign peptic ulceration. J Clin Pathol 1981;34:320-37.

5 Dubois M, Gilles KA, Hamilton JK, Rebers PA, Smith F. Colorimetric method for determination of sugars and related substances. Anal Chem 1956;28:350-6.

- Hounsell EF, Feizi T. Gastrointestinal mucins. Structures and antigenicities of their carbohydrate chains in health and disease. Med Biol 1982;60:227-36.

7 Pereira MEA, Kisailus EC, Gruezo F, Kabat EA. Immunochemical studies on the combining site of the blood group $\mathrm{H}$-specific lectin from Ulex europeus seeds. Arch Biochem Biophys 1978; 185: 108-15.

8 Watkins WM. Biochemistry and genetics of the $\mathrm{ABO}$, Lewis and $\mathbf{P}$ blood group systems. In: Harris $\mathbf{H}$, Hirschhorn $\mathbf{K}$, eds. Advances in human genetics. vol 10. London: Plenum Publishing Co, 1980:1-136.

' Dzierzkowa Borodej W, Seyfried H, Nicholls M, Reid M, Marsh WL. The recognition of water-soluble I blood group substance. Vox Sang 1970;18:222-34.

${ }^{10}$ Szulman AE. Chemistry, distribution and function of blood group substances. Ann Rev Med 1966; 17:307-22.

" Gooi HC, Schlessinger J, Lax I, Yarden Y, Libermann TA, Feizi T. Monoclonal antibody reactive with the human epidermalgrowth-factor receptor recognizes the blood-group- $A$ antigen. Biosci Reps 1983;3:227-36. 
12 Feizi T. Monoclonal antibodies point to carbohydrate structures as tumour-associated antigens. Med Biol 1983;61:144-6.

${ }^{13}$ Feizi T, Gooi HC, Childs RA, et al. Tumour-associated and differentiation antigens of the carbohydrate moieties of mucintype glycoproteins. Biochem Soc Trans 1984;12:590-5.

${ }^{14}$ Gooi HC, Williams LK, Uemura K, et al. A marker of human primitive endoderm defined by a monoclonal antibody involves type 1 blood group chains. Mol Immunol 1983;20:607-13.

is Magnani JL, Nilsson B, Brockhaus M, et al. A monoclonal antibody-defined antigen associated with gastrointestinal cancer is a ganglioside containing sialylated lacto-Nfucopentaose II. J Biol Chem 1982;257:14365-9.
${ }^{16}$ Picard JK, Feizi T. Carbohydrate antigens on glycoproteins of the neoplastic and uninvolved mucosae of patients with carcinoma of the stomach and colon. Biochem Soc Trans 1984; 12:651-3.

Requests for reprints to: Dr T Feizi, Applied Immunochemistry Research Group, Clinical Research Centre, Watford Road, Harrow, Middlesex HA1 3UJ, England. 